\title{
Studies on Sintered-Type Alkaline Storage Batteries. VII Effect of Cobalt on the Positive Plates of Sintered-Type Alkaline Storage Batteries*
}

\author{
Daijirō Yamashita \\ Faculty of Science and Engineering, Ritsumeikan University. \\ Tojiin Kitamachi, Kita-ku, Kyoto \\ Received June 25, 1963
}

\begin{abstract}
The author studied the effects of cobalt on the positive plates of sintered-type alkaline storage batteries by the experiments as follows.

(1) Charge-discharge curve of the active material of Ni-Co system.

(2) Durability test (capacity change by repeating charge-discharge for long period).

(3) Low rate charge test.

(4) X-ray diffraction diagram and electronmicrophotograph of active material.

According to these experimental results, charge-discharge potential dropped with increasing content of cobalt and active material seems to be solid solution $(\mathrm{Ni}$, Co) $(\mathrm{OH})_{2}$ up to $20 \% \mathrm{Co}$, but mixture of $(\mathrm{Ni}, \mathrm{Co})(\mathrm{OH})_{2}$ and $\mathrm{Co}(\mathrm{OH})_{3}$ over $30 \%$. The availability of active material increased by only $5 \%$ addition of cobalt.

Capacity drop by charge-discharge for long period and by low rate charge may be fairly prevented by the addition of cobalt.

This behavior of cobalt is probably due to the formation of solid solution $(\mathrm{Ni}$, Co) $(\mathrm{OH})_{2}$ in active material.
\end{abstract}

\section{Introduction}

The addition of cobalt to the active material of positive plates was applied in the practical use of $\mathrm{Ni}-\mathrm{Cd}$ alkaline storage batteries ${ }^{11}$.

S. Januszkiewicz reported ${ }^{2)}$ that the addition of cobalt results to raise the availability of active material and the author studied on the reaction mechanism and on the effects on capacity change by repeating charge-discharge and on low rate charge, which were not yet reported in details.

\section{Experimental}

\subsection{Grid}

As previously reported ${ }^{3), 4)}$, the iron nets of 14 meshes were spotwelded on an iron plate frame $30 \times 30 \mathrm{~mm}$ wide and annealed after nickel plating.

\subsection{Sintering}

Nickel carbonyl of apparent dencity $1.0 \mathrm{~g} / \mathrm{cc}$ was used and sintered at $930^{\circ} \mathrm{C}$ for $15 \mathrm{~min}$. under hydrogen atomosphere. The porosity of the product was about $80 \%$.

\subsection{Charge-discharge Curve of $\mathrm{Ni}-\mathrm{Co}$ Active Material}

Positive plates (Table 1) were prepared as follows. After preheating at $220^{\circ} \mathrm{C}$ for $10 \mathrm{~min}$., plaques were thrown into the fused mixture of nickel and cobalt nitrates and repeated for four times to heat at $220^{\circ} \mathrm{C}$ for $30 \mathrm{~min}$. and to throw, then plaques were electrolytically reduced in $25 \% \mathrm{KOH}$ solution at $80^{\circ} \mathrm{C}$ and dried. The plates which have no cobalt were used as standard and were charge-discharged under $0.20 \mathrm{~A}$ and all other plates were charge-discharged under the same hour rate. Potential curve was obtained by use of potentiometric autobalance recorder, referring its potential to $\mathrm{Hg} / \mathrm{HgO} / \mathrm{N}-\mathrm{KOH}$ standard electrode. These curves are shown in Fig. 1.

Charge curve : Potential falls with increasing

* Presented partly at 29th Annual Meeting of Electrochem. Soc. Japan held on April 30, 1962 at Sendai.

The original written in Japanese can be seen in Denki-Kagaku 31, 228, (1963). 
Table 1 Positive Plates Containing Cobalt

\begin{tabular}{l|l|l|l|l|c|c|c|c|c|c|c}
\hline \multicolumn{1}{c|}{ No. of plates } & \multicolumn{1}{c|}{1} & \multicolumn{1}{c|}{2} & \multicolumn{1}{c|}{3} & \multicolumn{1}{c|}{4} & \multicolumn{1}{c|}{5} & \multicolumn{1}{c|}{6} & \multicolumn{1}{c|}{7} & \multicolumn{1}{c|}{8} & 9 & 10 & 11 \\
\hline Co content (\%) & \multicolumn{1}{c|}{0} & 5 & 10 & 20 & 30 & 50 & 70 & 80 & 90 & 95 & 100 \\
Wt. of plaque (g) & 3.63 & 3.53 & 3.31 & 3.21 & 3.78 & 4.06 & 3.83 & 3.88 & 3.86 & 4.10 & 3.72 \\
Wt. of nickel powder (g) & 1.74 & 1.72 & 1.47 & 1.38 & 1.95 & 2.10 & 1.96 & 1.91 & 1.98 & 2.22 & 1.82 \\
Thickness of plate (mm) & 1.5 & 1.5 & 1.4 & 1.4 & 1.6 & 1.7 & 1.6 & 1.6 & 1.6 & 1.7 & 1.6 \\
Wt. of active material* & 1.11 & 1.03 & 0.84 & 0.83 & 1.27 & 1.35 & 1.33 & 1.36 & 1.62 & 1.42 & 1.49 \\
Capacity calculated(AH)* & 0.323 & 0.299 & 0.245 & 0.241 & 0.370 & 0.387 & 0.383 & 0.392 & 0.465 & 0.407 & 0.430 \\
Initial capacity (AH)** & 0.170 & 0.240 & 0.220 & 0.200 & 0.350 & 0.416 & 0.310 & 0.286 & 0.280 & 0.240 & 0.233 \\
Availability (\%) & 52.6 & 80.3 & 90.0 & 83.0 & 94.5 & 107.5 & 81.0 & 73.1 & 60.1 & 59.0 & 54.2 \\
\hline
\end{tabular}

* Capacity is calculated considering weight increase of plaque after drying as $\mathrm{Ni}(\mathrm{OH})_{2}$.

** Capacity is obtained by discharging to 0.5 volt.

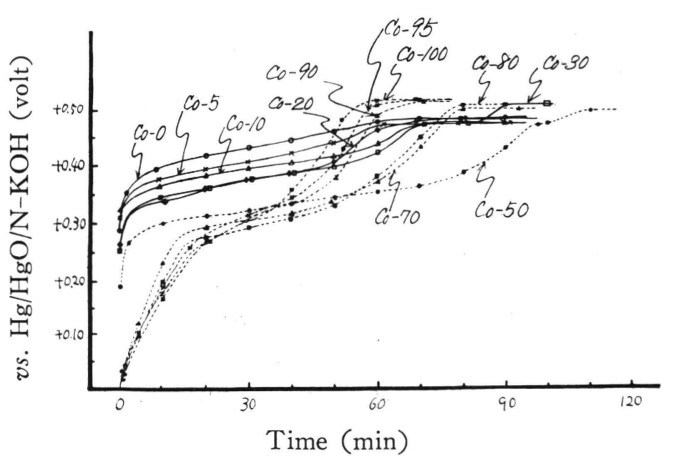

Fig. 1(A) Charge curve $\left(25^{\circ} \mathrm{C}\right)$.

content of cobalt, but at the end of charge the potential almost equal to that of the sample which has no cobalt. Especially high potential appears at the sample of $30 \%$ cobalt and it keeps almost constant to that of $100 \% \mathrm{Co}$, while initial potential falls with increasing content of cobalt.

Discharge curve : Potential falls suddenly even at the sample of $5 \%$ cobalt, but keeps constant to that of $30 \%$ cobalt, while the availability of active material increases with increasing content of cobalt.

Potential falls as the cobalt content increases and it shows extremely low value at that of about $100 \%$ cobalt.

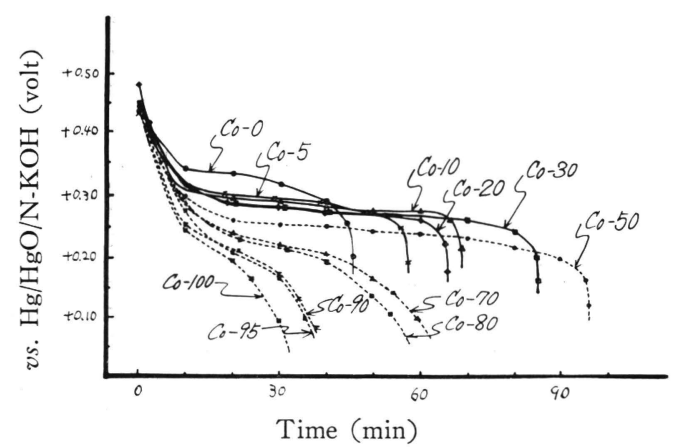

Fig. 1(B) Discharge curve $\left(25^{\circ} \mathrm{C}\right)$.

\subsection{Durability Test}

\subsubsection{Preparation of Positive Plates for Durability Test}

Positive plates were prepared along the method as shown in Table 2 and the properties of the plates are listed in Table 3 .

\subsubsection{Durability Test}

Positive plates obtained by the above mentioned method were fixed between two negative pocket type cathodes and added $25 \% \mathrm{KOH}$ solution as electrolyte. Capacity change caused by repeating charge-discharge were measured with use of automatic charge-discharge apparatus.

Charge-discharge condition: (A) $0.20 \mathrm{~A} 40$

Table 2 Impregnation Methods (A and B)

\begin{tabular}{l|l}
\hline \hline \multicolumn{1}{c|}{$\mathrm{A}$} & \multicolumn{1}{c}{$\mathrm{B}$} \\
\hline 1) Heating plaques at $220^{\circ} \mathrm{C}$ for $10 \mathrm{~min}$. & \\
2) Throwing in to fusing mixture of $\mathrm{Ni}\left(\mathrm{NO}_{3}\right)_{2} \cdot 6 \mathrm{H}_{2} \mathrm{O}$ and $\mathrm{Co}\left(\mathrm{NO}_{3}\right)_{2} \cdot 6 \mathrm{H}_{2} \mathrm{O}$ at $60^{\circ} \mathrm{C}$.
\end{tabular}


Table 3 Positive Plates for Durability Test

\begin{tabular}{|c|c|c|c|c|c|c|c|c|}
\hline \multirow{3}{*}{$\begin{array}{l}\text { Impregnation method } \\
\text { of plates }\end{array}$} & \multicolumn{5}{|c|}{ (A) } & \multicolumn{3}{|c|}{ (B) } \\
\hline & \multicolumn{5}{|c|}{$\begin{array}{l}\text { Plaques preheated at } 220^{\circ} \mathrm{C} \text { for } 10 \mathrm{~min} \text {. } \\
\text { are thrown into fused nitrate and elec- } \\
\text { trolytically reduced in } 25 \% \mathrm{KOH} \text {. }\end{array}$} & \multicolumn{3}{|c|}{$\begin{array}{l}\text { Plaques preheated at } 220^{\circ} \mathrm{C} \\
\text { for } 10 \mathrm{~min} \text {. are thrown into } \\
\text { fused nitrate and soaked in } \\
25 \% \mathrm{KOH} \text { at } 80^{\circ} \mathrm{C} \text { for } 16 \mathrm{~h} \text {. }\end{array}$} \\
\hline & 12 & 13 & 14 & 15 & 16 & 17 & 18 & 19 \\
\hline Cobalt content $(\%)$ & 0 & 5 & 10 & 20 & 30 & 0 & 5 & 10 \\
\hline Wt. of plaque (g) & 3.63 & 3.43 & 3.45 & 3.60 & 3.60 & 3.79 & 3.80 & 4.05 \\
\hline Wt. of active material $(\mathrm{g})$ & 0.351 & 0.275 & 0.362 & 0.385 & 0.309 & 0.571 & 0.445 & 0.543 \\
\hline Capacity celculated $(\mathrm{AH})$ & 0.102 & 0.080 & 0.105 & 0.112 & 0.090 & 0.151 & 0.115 & 0.136 \\
\hline Initial capacity $(\mathrm{AH})$ & 0.087 & 0.067 & 0.107 & 0.094 & 0.064 & 0.140 & 0.120 & 0.133 \\
\hline Availability $(\%)$ & 85.6 & 71.3 & 102.0 & 84.0 & 71.3 & 93.0 & 104.5 & 97.9 \\
\hline
\end{tabular}

min. charge, $0.20 \mathrm{~A} 20 \mathrm{~min}$. discharge, (B) 0.30 A $40 \mathrm{~min}$. charge, $0.30 \mathrm{~A} 20 \mathrm{~min}$. discharge. At 1000 cycles electrolyte was replaced.

The results obtained in this test are shown in Figs. 2 and 3. The capacity change is shown regarding initial capacity as 100 .

According to these test, the effects of cobalt appeared distinctly after 1000 cycles and the degree of capacity drop decreases with increasing content of cobalt.

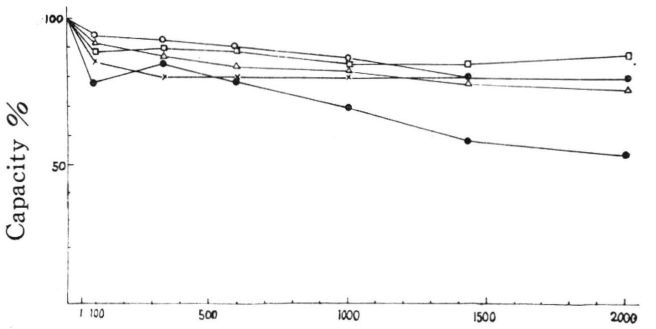

Charge-discharge cycle

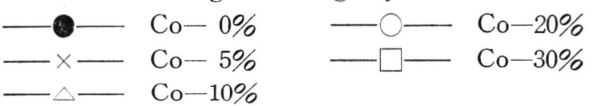

Fig. 2 Capacity change by durability test (Table $2 \mathrm{~A}$ ).

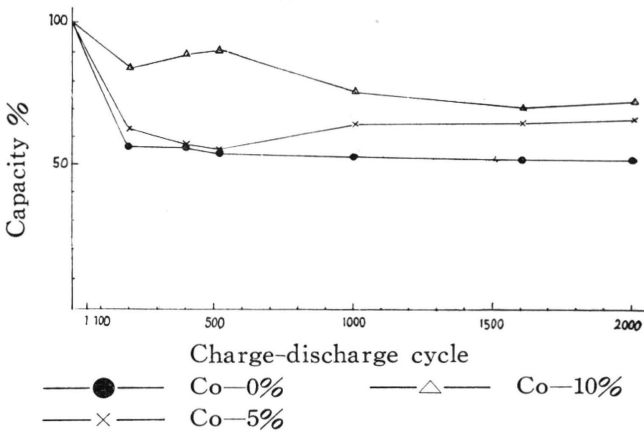

Fig. 3 Capacity change by durability test (Table 2 B).

\subsection{Low Rate Charge Tests}

In order to investigate the influence of low rate charge, plates containing cobalt $<30 \%$ as shown in Table 2 were overcharged to $150 \%$ of initial capacity under $0.20 \mathrm{~A}$ and discharged under the same rate and these capacity was regarded as 100 .

Then after charging under 20 95 hours rate, capacity was measured under $0.20 \mathrm{~A}$ discharge. These results are shown in Fig. 4. The capacity drops remarkably at $0 \%$ cobalt, but become fairly small at $5 \%$ cobalt and extremely small at $30 \%$ cobalt.

\section{$2.6 \mathrm{X}$-ray Diffraction Diagram of Ac- tive Material}

\subsubsection{Change of $\mathrm{X}$-ray Diffraction Di- agram by Repeating Chare-dis- charge}

Every sample contains nickel hydroxide in large amount of nickel powder. Fig. 5 shows $\mathrm{X}$-ray diffraction diagram of active material in discharged state (in the plates prepared along

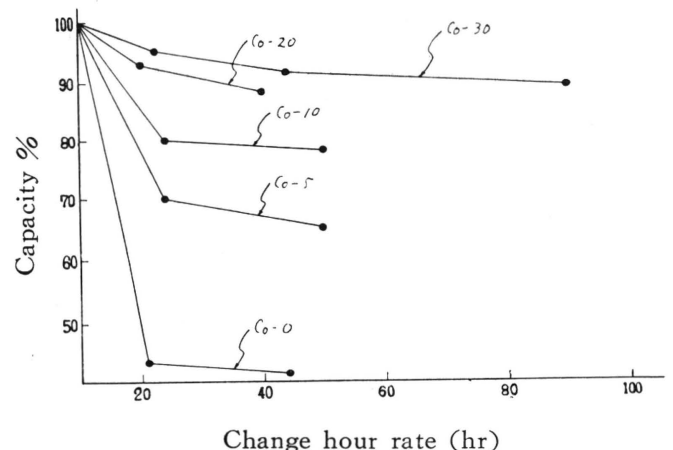

Fig. 4 Capacity change by low rate charge. 
(a)

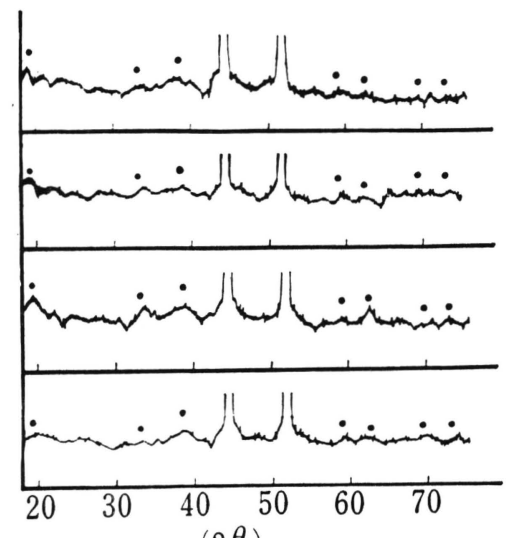

$(2 \theta)$

(a) 2,000 cycles Co $10 \%$ (c) 2,000 cycles Co $0 \%$ (b) 2,000 cycles Co $5 \%$ (d) 2 cycles Co $0 \%$

Fig. 5 Change of $\mathrm{X}$-ray diagram by chargedischarge $\left(\mathrm{CuK}_{\alpha}\right)$.

the method shown in Table $2(\mathrm{~A})$ ) at 2000 cycles. In this diagram the line of the plates containing no cobalt grows fairly, but that of the plates containing cobalt grows relatively little.

\subsubsection{X-ray Diffraction Diagram of Active Material}

Fig. 6 shows X-ray diffraction diagram of active material and the samples (a), (b), (c) and (d) were prepared as follows. In case of (c) as shown in Fig. 7, several nickel nets of about 50 meshes were piled tightly in plastic vessel $\mathrm{A}$ and nickel nitrate fused at $80^{\circ} \mathrm{C}$ was poured into this vessel until about half of the depth of nickel net was immersed. The electrolysis was carried out, using $25 \% \mathrm{KOH}$ as electrolyte, vessel $\mathrm{A}$ as cathode and nickel net $\mathrm{B}$ as anode under $10 \mathrm{~A} / \mathrm{dm}^{2}$ at $80^{\circ} \mathrm{C}$ for $20 \mathrm{~min}$. Then the active material was taken out, washed and dried (this sample is considered as that prepared along the method shown in Table $2 \mathrm{~A}$ ).

Samples (a), (b) and (d) were prepared as follows. Fused salt heated in air at $220^{\circ} \mathrm{C}$ for 1 hour was soaked in $25 \% \mathrm{KOH}$ at $80^{\circ} \mathrm{C}$ for 16 hours and then washed and dried. Sample (a) contains $10 \%$ cobalt, (b) $5 \%$ cobalt and (c) $0 \%$ cobalt.

Shapes of diffraction diagram were different from each other and the strength of diffraction line increases and diffusion degree decreases in (a)

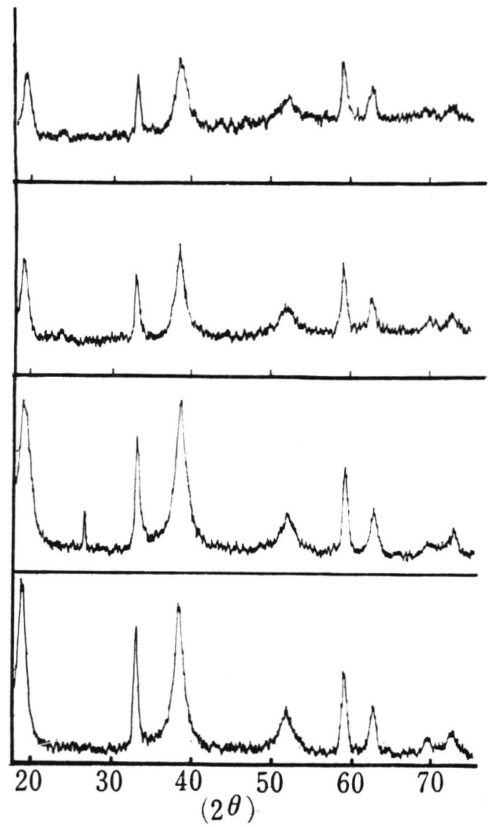

(a) Fused salt (Co 10\%). Heating at $220^{\circ} \mathrm{C}$, for $1 \mathrm{~h}$. Soaking at $80^{\circ} \mathrm{C}$ in $25 \% \mathrm{KOH}$ for $16 \mathrm{~h}$.

(b) Fused salt (Co $5 \%$ ). Heating at $220^{\circ} \mathrm{C}$, for $1 \mathrm{~h}$. Soaking at $80^{\circ} \mathrm{C}$ in $25 \% \mathrm{KOH}$ for $16 \mathrm{~h}$.

(c) Fused salt (Co 0\%). Electrolyzing under $2 \mathrm{~A}$ for $20 \mathrm{~min}$ in $25 \% \mathrm{KOH}$ at $80^{\circ} \mathrm{C}$.

(d) Fused salt (Co $0 \%$ ). Heating at $220^{\circ} \mathrm{C}$, for $1 \mathrm{~h}$. Soaking at $80^{\circ} \mathrm{C}$ in $25 \% \mathrm{KOH}$ for $16 \mathrm{~h}$.

Fig. $6 \mathrm{X}$-ray diffraction diagram of active material.

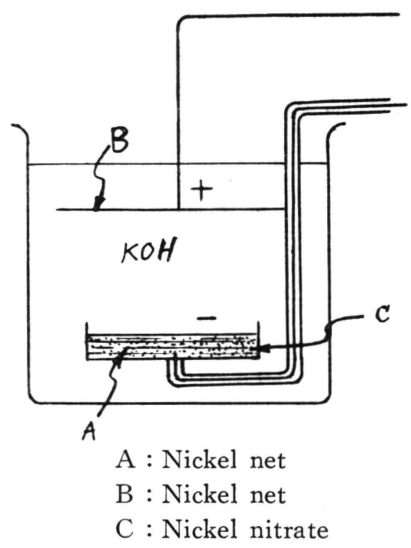

Fig. 7 Apparatus for reducing nickel nitrate. order of (a), (b), (c) and (d).

\subsection{Electron-microphotograph of Ac- tive Material}

To confirm the effects of cobalt, samples were prepared by the following three methods :- 
(a) Plaques were prepared as follows, nickel nets $30 \times 30 \mathrm{~mm}$ wide and of 200 and 50 meshes were alternately piled and their edges were griped by nickel frame. Plaques impregnated by nickel nitrate were electrolytically reduced in $25 \% \mathrm{KOH}$ solution at $80^{\circ} \mathrm{C}$. A nickel net of 200 meshes was taken out from the center of plaques was washed with water and dried with alcohol at room temperature. Nickel nets of $3 \times 3 \mathrm{~mm}$ wide were cut from edge and center of these nets were observed in deposited state.

(b) Plaques were prepared by the same method as (a). After heating impregnated fused salt at $220^{\circ} \mathrm{C}$ for 1 hour, plaques were soaked in $25 \% \mathrm{KOH}$ solution for 16 hours and washed and then observed like (a).

(c) Nitrate heated at $220^{\circ} \mathrm{C}$ for 1 hour was soaked in $25 \% \mathrm{KOH}$ solution for 16 hours and then dispersed in alcohol. The samples were observed after air drying. Representative examples prepared by (a), (b) and (c) methods are showh in Photo 1.

It is considered by this photograph that the dispersion of active material is produced by addition of cobalt. Moreover, the separation of needle crystal appears by the addition of cobalt.

\section{Discussion}

In the charge curve shown in Fig. 1 (A), the initial potential drops with increase of cobalt content to $20 \%$, but at the end of charge every plate has almost the same value. But over 30\% high potential appears especially at the end of charge and the potential equals to that of the plate of cobalt 100\%. According (a)

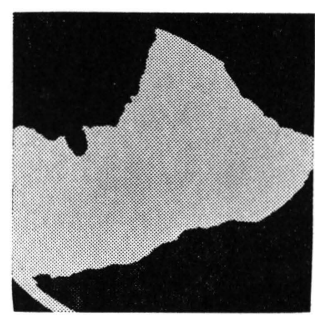

(b)

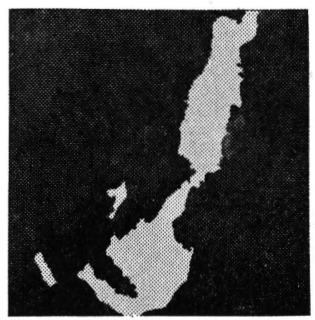

(c)

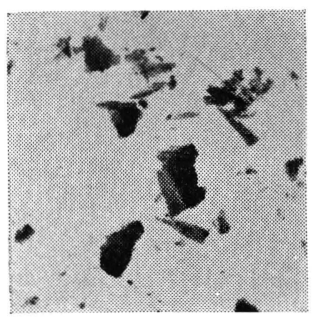

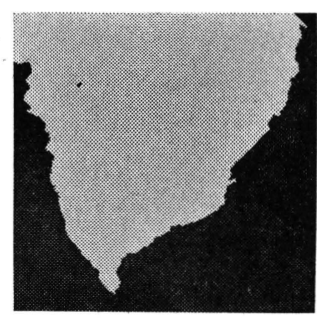
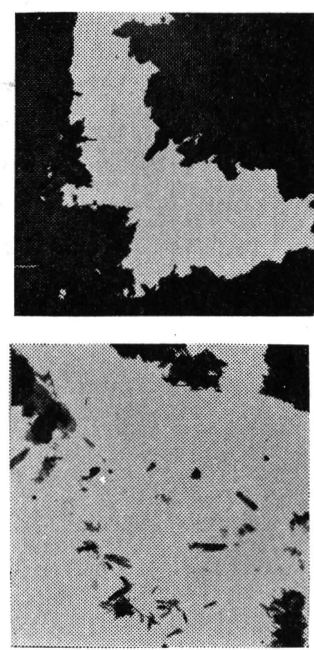

Co-5
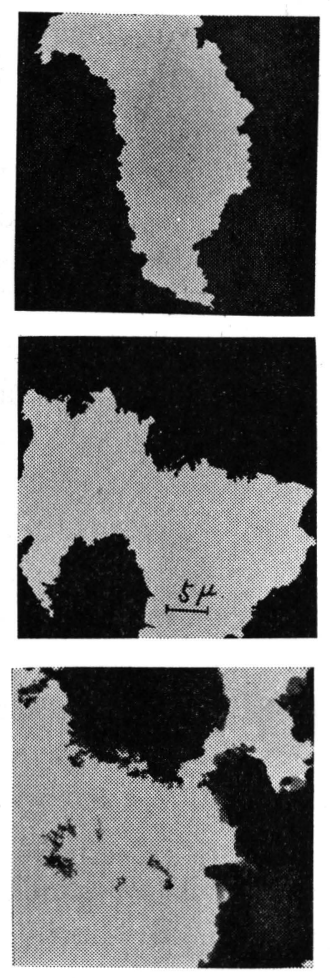

Co-10

(a) Active material separated on nickel net by electrolysis.

(b) Active material separated on nickel net by heating.

(c) Active material decomposed by heating, dispersed in alcohol, dried in room temp

(Black part is active material)

Photo 1 Electronmicrophotographs of active materials. 
to the X-ray diffraction diagram (Fig. 6), the intensity increase of diffraction lines of (a) cobalt $10 \%$ and (b) cobalt $5 \%$ was smaller than that of (d) cobalt $0 \%$ and the diffusion of lines was found in (a) and (b).

On the samples prepared as follows-after preheating at $220^{\circ} \mathrm{C}$ for 1 hour, the mixed nitrate was soaked in $25 \% \mathrm{KOH}$ solution for 16 hours and washed with water and dried-pale green nickel hydroxide has red grey color a little in the case of $<$ cobalt $20 \%$, but black grey color appears in the case of cobalt $20 \sim$ $30 \%$. This color tone is fairly similar to that in case of cobalt 100\%.

From these facts, cobalt was considered to exist as solid solution $(\mathrm{Ni}, \mathrm{Co})(\mathrm{OH})_{2}$ in case of $<20 \%$ and excess cobalt was to separate as $\mathrm{Co}(\mathrm{OH})_{3}$ in case of $>20 \%$ and therefore active material formed two phases.

It is considered that charge curve of cobalt $30 \%$ is corresponding to the charge curve of solid solution of $(\mathrm{Ni}, \mathrm{Co})(\mathrm{OH})_{2}$ and $\mathrm{Co}(\mathrm{OH})_{3}$. About discharge curve shown in Fig. 1 (B), initial potential drops suddenly by adding $5 \%$ cobalt and such state continues to that of cobalt $30 \%$.

Lasting time of discharge increase with increasing cobalt content within this range. As seen in Fig. 6 (a), (b), when cobalt solutes in solid state, it is considered that crystals become unstable and charging becomes easy due to the increase of activity and therefore the availability of active material increases. At cobalt $50 \%$, the availability was maximum, probably because two phases of active solid solution and $\mathrm{Co}(\mathrm{OH})_{3}$ exist, but the potential remarkably drops owing to the addition of cobalt. At cobalt $100 \%$, the potential of discharge curve drops suddenly and it is considered that Co $(\mathrm{OH})_{3}$ already grows in discharged state and therefore active material stays unchanged by charging.

On the durability tests of the sample prepared along the method shown in Table $2 \mathrm{~A}$, the capacity drop begins after 300 cycles about the one containing no cobalt and the capacity keeps almost constant value after 500 cycles in case of containing cobalt.

At 2000 cycles, the capacity difference between the plates is remarkable. On the other hand, according to the $\mathrm{X}$-ray diffraction diagram (Fig. 5), the growth of diffraction line decreases with decreasing capacity drop. In the case of the sample prepared by the method shown in Table 2 (B), the effect of cobalt appears after 1000 cycles. Compared with (a), (b) and (d) in Fig. 6, the drop of capacity decreases with decreasing strength of line and with increasing diffusion of line. The drop of capacity decreases with increasing addition of cobalt. When cobalt solutes in active material, the activation of active material rises and cobalt cotinues this behavior.

According to Fig. 3, initial capacity drop is remarkable and it is probably because stabilization and coaguration of active material happens. to occur by heating after impregnation. On the contrary, at cobalt $10 \%$, initial drop is little, because cobalt prevents these action.

In Fig. 4, charging becomes easy due to the activation of active material by cobalt solid solution, therefore capacity drop is considered small by low rate charge.

\section{Conclusion}

The availability of active material of sintered-type alkaline storage batteries increases. by the addition of cobalt. Also, charge and discharge potential drops are both small. Capacity decrease by charge-discharge for a long period is prevented only by $5 \%$ cobalt addition. And also, capacity drop by low rate charge is decreased. It is considered that these phenomena are attributed to the activation of crystals by the formation of cobalt solid solution in active material and by the dispersion of crystals originated from activation.

The author wishes to acknowledge in particular the assistance in $\mathrm{X}$-ray analysis by $\mathrm{Mr}$. Masao Fukui, University of Kyoto Polytechnic and Textile. $\mathrm{He}$ is also grateful to $\mathrm{Mr}$. Y. Yamamoto, Mr. M. Ozasa and Mr. K. Hayashi 
for their co-operation in this investigation.

Literature :

1) T.A. Edison, U.S. Pat. 678,722 (1901); U.S. Pat. 1,083,356 (1914).

2) S. Januszkiewicz, Proceedings of Annual Power
Source Conference 13, 75 (1959).

3) D. Yamashita, Y. Takeuchi, Denki-kagaku 29, 162 (1961).

4) D. Yamashita, Y. Yamamoto, Y. Takeuchi, Kōgyo Kagaku Zasshi 65, 10 (1962). 